\title{
Levels of EGF and VEGF in patients with primary and secondary Sjögren's syndrome
}

\author{
Katarzyna J. Błochowiak ${ }^{1, A-F}$, Dorota Trzybulska ${ }^{2, B, C, E, F}$, Anna Olewicz-Gawlik',A,B,E,F, Jan J. Sikora ${ }^{3, E, F}$, \\ Michalina Nowak-Gabryel ${ }^{4, B, E, F}$, Jarosław Kocięcki ${ }^{4, E, F}$, Henryk Witmanowski ${ }^{5, E, F}$, Jerzy Sokalski, ${ }^{6, A, E, F}$ \\ ${ }^{1}$ Department of Dental Surgery, Poznan University of Medical Sciences, Poland \\ ${ }^{2}$ Department of Rheumatology and Clinical Immunology, Poznan University of Medical Sciences, Poland \\ ${ }^{3}$ Department of Immunology, Poznan University of Medical Sciences, Poland \\ ${ }^{4}$ Department of Ophthalmology, Poznan University of Medical Sciences, Poland \\ ${ }^{5}$ Department of Plastic, Reconstructive and Aesthetic Surgery, Nicolaus Copernicus University in Toruń, Collegium Medicum in Bydgoszcz, Poland \\ ${ }^{6}$ Department of Oral Surgery, Poznan University of Medical Sciences, Poland \\ A - research concept and design; B - collection and/or assembly of data; $\mathrm{C}$ - data analysis and interpretation; \\ $D$ - writing the article; $E$ - critical revision of the article; $F$ - final approval of the article
}

Address for correspondence

Katarzyna Błochowiak

E-mail:kasia@naszdentysta.com.pl

Funding sources

This study was supported by grant

No. 502-14-02212331-09591 from

the Poznan University of Medical Sciences.

Conflict of interest

None declared

Received on November 20, 2016

Reviewed on March 15, 2017

Accepted on April 27, 2017

\begin{abstract}
Background. Aberrant angiogenesis plays a role in the pathogenesis of Sjögren's syndrome (SS).

Objectives. The aim of this study was to compare the levels of vascular endothelial growth factor (VEGF) and epidermal growth factor (EGF) in stimulatory parotid saliva and in serum in healthy subjects (HS), patients with primary SS (pSS) and secondary SS (SSS) and to evaluate the expression of EGF, proangiogenic VEGF 165 and antiangiogenic $\mathrm{VEGF}_{165} \mathrm{~b} \mathrm{mRNA}$ isoforms. Additionally, we determined the salivary levels of serine/arginine splicing factor (SRSF1), which regulates VEGF 165 and VEGF 1656 expression.
\end{abstract}

Material and methods. The study comprised 34 women (16 with pSS and 18 with SSS) and healthy subjects for blood and saliva sampling. EGF and VEGF levels in saliva and serum and salivary SRSF1 levels were determined by enzyme-linked immunosorbent assay (ELISA). The expression of VEGF 165, VEGF 165 and EGF in peripheral blood mononuclear cells (PBMC) was evaluated by quantitative polymerase chain reaction (qPCR).

Results. There were no differences in the levels of EGF, VEGF, SRSF1 and in the expression of the EGF, VEGF 165 and VEGF ${ }_{165} b$ between $\mathrm{HS}$ and SS patients, or between pSS and sSS patients. The salivary levels of $\mathrm{VEGF}_{165}$ and EGF were significantly higher in pSS, SSS and HS than serum levels. Levels of SRSF1 correlated positively with VEGF and EGF levels. Levels of EGF, VEGF and SRSF1 correlated with each other.

Conclusions. The balance of VEGF isoforms is not disturbed in SS. Saliva is more sensitive for the detection of EGF and VEGF than serum, but salivary levels of those proteins are not representative for SS.

Key words: Sjögren's syndrome, angiogenesis, vascular endothelial growth factor, epidermal growth factor

DOI

10.17219/acem/70800

Copyright

Copyright by Author(s)

This is an article distributed under the terms of the

Creative Commons Attribution Non-Commercial License

(http://creativecommons.org/licenses/by-nc-nd/4.0/) 


\section{Introduction}

Sjögren's syndrome (SS) is a systemic autoimmune disease characterized by periductal mononuclear cell infiltrate in the salivary and lachrymal glands, autoimmunization, injuries to endothelial cells and their subsequent apoptosis. ${ }^{1,2}$ Inflammatory cells secrete growth factors, proteases and cytokines that induce extracellular matrix degradation, endothelial cell growth and migration promoting angiogenesis. Neovessels may contribute to the perpetuation of inflammation by recruiting more inflammatory cells to the inflammation site. Angiogenic factors induce endothelial cells to express adhesive molecules, cytokines and chemokines, which have additional stimulatory effects on chronic inflammation. ${ }^{3}$

One of the major proangiogenic regulators is vascular endothelial growth factor (VEGF). It promotes the migration of inflammatory cells into the extracellular matrix by inducing vascular permeability and endothelial cell expression of adhesion molecules, of which elevated levels are observed in SS. ${ }^{3}$ VEGF exerts its biological function by binding to its receptors: VEGFR-1, VEGFR-2 and VEGFR-3. ${ }^{4,5}$ The main isoform VEGF $_{165}$ has 165 amino acids in the mature structure. Two families of VEGF proteins are formed by an alternative splice-acceptor-site to give to 2 distinctive $\mathrm{C}$-terminal sequences differing in their angiogenic properties. ${ }^{6-8}$ These 2 isoforms bind to the VEGFR-2 with the same affinity, but the binding of $\mathrm{VEGF}_{165} \mathrm{~b}$ results in an insufficient tyrosine phosphorylation/activation of VEGFR-2 and incomplete or transient downstream signaling, which leads to an impaired angiogenic response. ${ }^{6,9}$ The isoforms VEGF $_{165}$ and VEGF $_{165} \mathrm{~b}$ account for a substantial proportion of the total VEGF. ${ }^{9}$ The balance of the VEGF $\mathrm{Vxx}_{\mathrm{xx}}$ (proangiogenic) and VEGF $\mathrm{xxx}_{\mathrm{x}} \mathrm{b}$ (antiangiogenic) families may have a crucial role in controlling angiogenesis in health; an imbalance can underpin pathological angiogenesis. Primarily, the influence of $\mathrm{VEGF}_{165}$ and $\mathrm{VEGF}_{165} \mathrm{~b}$ on cancerogenesis was examined. ${ }^{4,10-12}$ Similar patomechanisms between pro- and antiangiogenic also seem to occur in autoimmune diseases and coexistent chronic inflammation influencing their development by stimulating or inhibiting angiogenesis. The mechanism regulating the expression of pro- and antiangiogenic isoforms of $V E G F$ is not known. Many growth factors and other proteins can change the proportion of $V E G F_{165}$ and $V E G F_{165} b$ and regulate alternative splicing, e.g., insulinlike growth factor 1 (IGF-1), transforming growth factor alpha 1 (TGF- $\alpha 1$ ), transforming growth factor beta 1 (TGF- $\beta 1$ ) and its co-regulator-serine-rich protein splicing factor 1 (SRSF1). ${ }^{9}$ The serine/arginine rich proteins regulate binding to exon-splicing enhancers and silencers and intronic enhancers and silencers in pre-mRNA. Exon splicing depends on the balance of splicing factors activities.

So far, most studies have focused on the serum levels of VEGF and epidermal growth factor (EGF) and their local expression in salivary gland biopsy specimens in SS patients. Therefore, this is also the first trial assessing the possible role of $V E G F$ splice variants: $V E G F_{165}$ and $V E G F_{165} b$ and SRSF1 in SS. In SS, pathological changes are more advanced locally in comparison to systemic ones. Proinflammatory cytokine production is disordered in salivary glands as well as in peripheral blood. In SS patients there are particular differences between leukocytes in the peripheral blood and in the salivary glands. ${ }^{13}$

The aim of this study was to compare the levels of VEGF and EGF in stimulated parotid saliva and in serum in patients with primary SS (pSS) and secondary SS (sSS) and in healthy subjects (HS), as well as to evaluate the expression of $E G F$ and isoforms $V E G F_{165}$ and $V E G F_{165} b$ in PBMC in pSS, sSS and HS. Furthermore, the levels of SRSF1 in parotid saliva were compared.

\section{Material and methods}

\section{Study groups}

The study comprised 34 women with SS (16 with pSS and 18 with sSS) aged 41.5 (interquartile ranges (IQR): 28.5) in pSS group and 56.0 (IQR: 21.0) in sSS group, respectively (Table 1), fulfilling the 2002 American-European Consensus Group (AECG) classification criteria. Our study diagnosis of pSS required 4 out of 6 criteria, including the presence of the antibody to SS-A/SS-B. The diagnosis of sSS has not yet been addressed by the AECG. In practice, we required the patients to fulfill the criteria for pSS and also to meet the American College of Rheumatology (ACR) criteria for an established connective-tissue disease (CTD), such as rheumatoid arthritis (RA), systemic lupus erythematosus (SLE) or mixed connective tissue disease (MCTD). ${ }^{1,2,14}$ Patients were recruited consecutively in 2013 from the Department of Rheumatology and Clinical Immunology. Exclusions to the diagnosis of SS included previous radiotherapy to the head and neck, lymphoma, sarcoidosis, graft-versus-host disease, infections with hepatitis $\mathrm{C}$ virus (HCV), human T-cell lymphotropic virus type 1 (HTLV-I) and human immunodeficiency virus (HIV). The patient's history was taken and physical and dental examinations were performed in the Department of Oral Surgery at Poznan University of Medical Sciences by dentist for each subject. Laboratory assessments included routine measurements of erythrocyte sedimentation rate (ESR) (Westergren method) ${ }^{15}$ and detection of antinuclear antibodies (ANA) by indirect immunofluorescence (IIF) on HEp-20-10 cells (Euroimmun, Lubeck, Germany) and their differentiation using ANA Profile3 (Euroimmun, Lubeck, Germany). Xerostomia (assessed by patients) was measured by a visual analogue scale (VAS) and Fox's test. To assess ocular sicca symptoms, Schirmer's test was carried out. Both eyes were tested at the same time. Schirmer's test was performed without anesthesia before the procedure. Special paper strips (Alcon Laboratory, Fort Worth, USA) 
were placed under the lower eyelid of each eye lateral to the canthus away from the cornea. The patients kept their eyes closed for $5 \mathrm{~min}$. Mechanical irritation resulted in the production of tears. After 5 min the paper was removed and measured to check how moist it was. The sign of normal tear production was indicated by the presence of more than $10 \mathrm{~mm}$ of moisture on the filter paper after $5 \mathrm{~min}$. Both eyes normally release the same amount of tears. A score between 5-10 mm was a sign of mild to moderate dry eye. Less than $5 \mathrm{~mm}$ of moisture on the filter paper after 5 min was a sign of severe dry eye and was a diagnostic criterion for SS. To report the severity of dry eye we used the average of both eyes. ${ }^{16,17}$

In the study, 15 age-matched healthy donors from the Regional Centre of Blood Donation and Blood Treatment in Poznań formed the control group for serum sampling (healthy subjects, HS).

A total of 15 age-matched healthy donors of dental students and dentists formed the control group for saliva sampling (HS); it included 10 women and 5 men aged 23 (IQR: 5). Only patients without severe systemic diseases, who do not take any drugs, and without symptoms of dry mouth and xerostomia were classified to the control group.

The protocol for this study was approved by the Bioethics Committee of Poznan University of Medical Sciences, Poland (No. 211/2013). Written informed consent was obtained from every subject before any study procedure was carried out.

\section{Blood and saliva sampling}

Peripheral blood samples were collected from the antecubital vein into BD Vacutainer Rapid Serum Tubes (Becton; Dickinson and Company, New York, USA). Peripheral blood mononuclear cells (PBMC) were isolated from $3 \mathrm{~mL}$ of fresh EDTA whole blood with the use of Lymphocyte Separation Medium 1077 (PAA, Pasching, Austria), in accordance with the manufacturer's protocol. Next, the cells were lysed in $1 \mathrm{~mL}$ of TRIzol (Invitrogen, Carlsbad, USA).

Parotid saliva was collected directly from the parotid gland opening with Lashley cups into Eppendorf tubes after stimulation with 3\% citric acid. Gauze swabs soaked with citric acid were put on the tongue every minute. Saliva sampling lasted as long as was needed to collect $2 \mathrm{~mL}$ saliva. Saliva was not centrifuged according to the instruction recommended in the applied tests. We did not add any proteinase inhibitors. About $2 \mathrm{~h}$ before sampling, the patients refrained from eating, drinking, rinsing their mouths and brushing their teeth. The saliva, sera and lysed PBMC were stored at $-70^{\circ} \mathrm{C}$.

\section{RNA extraction, reverse transcription and quantitative polymerase chain reaction}

Extraction of RNA, reverse transcription and quantitative polymerase chain reaction (qPCR) were carried out as described earlier. ${ }^{18}$ The sequences used for EGF amplification were: F: 5'CCTGATGGGAAACGATGTC3', R: 5'GTGAGGAACAACCGCTAC3'. The sequences for $V E G F_{165}$ and $V E G F_{165} b$ were the same as described previously. ${ }^{19}$

\section{Measurement of studied proteins}

Circulating EGF and VEGF 165 levels in the saliva and serum were determined by ELISA (R\&D Systems, Minneapolis, USA) with a sensitivity of less than $5.0 \mathrm{pg} / \mathrm{mL}$ for $\mathrm{VEGF}_{165}$ and $0.7 \mathrm{pg} / \mathrm{mL}$ for EGF. Soluble SRSF1 levels in parotid saliva were determined by ELISA (EIAab SCIENCE, Wuhan, China) with a sensitivity of less than $0.078 \mathrm{ng} / \mathrm{mL}$. Absorbance was measured with a ELx800 96-well Microplate Reader and KC junior 1.11 (Bio-Tek Instruments, Vermont, USA).

\section{Statistical analysis}

The calculations were carried out with Microsoft Excel 2010 and STATISTICA v. 10 software (StatSoft Inc., Tulsa, USA). The distributions obtained at each step of data processing were evaluated for normality using the ShapiroWilk test. Depending on the number of groups analyzed, the differences between them were tested using the MannWhitney $U$ test or the Kruskal-Wallis one-way analysis of variance (ANOVA) by ranks, followed by post hoc multiple comparisons of the mean ranks. Spearman's rank correlation analysis was used to find the associations between the levels of selected cytokines and other laboratory and clinical parameters of SS activity. All the data is expressed as medians with interquartile ranges (IQR). Differences were considered to be statistically significant at $\mathrm{p}<0.05$.

\section{Results}

\section{Demography}

All the subjects were of Caucasian origin. Table 1 and 2 present a demographic, laboratory and clinical profile of SS patients. The median age of the HS group for serum sampling (14 women and 1 man) was 49 (IQR: 14). The median age of the control group for saliva sampling (10 women and 5 men) was 23 (IQR: 5). The correlation between VEGF levels and age was studied in cancerogenesis. The VEGF expression was not correlated with age in patients with colon cancer. ${ }^{20}$ There were no differences in VEGF levels between the young control group and the elder group with prostate patients. ${ }^{21}$ There was no correlation between the age of healthy people without immunological, inflammatory and neoplastic disease and the VEGF concentration. ${ }^{22}$ The main criterion to classify patients to the control group was the elimination of the possible role of inflammatory, immunological and other diseases and drugs on the VEGF levels. 
Table 1. Characteristics of SS patients

\begin{tabular}{|c|c|c|}
\hline Clinical and laboratory data & pSS $(n=16)$ & sSS $(n=18)$ \\
\hline Age [years] & $41.5(28.5)$ & $56.0(21.0)$ \\
\hline $\mathrm{BMI}\left[\mathrm{kg} / \mathrm{cm}^{2}\right]$ & $24.65(7.60)$ & $23.55(5.30)$ \\
\hline Disease duration [years] & $4.5(4)$ & $3(9)$ \\
\hline RA, n [\%] & - & $7(38.89)$ \\
\hline SLE, n [\%] & - & $4(22.20)$ \\
\hline Others, n [\%] & - & $7(38.89)$ \\
\hline Westergren ESR [mm/h] & $23.5(31)$ & $19(15)$ \\
\hline ANA titer >1:160, n [\%] & $11(68.75)$ & 15 (83.33) \\
\hline SS-A, n [\%] & $10(62.50)$ & $10(55.55)$ \\
\hline SS-B, n [\%] & $7(43.75)$ & $4(22.22)$ \\
\hline Ro-52 & $10(62.50)$ & $11(61.11)$ \\
\hline dsDNA & 0 & $3(16.67)$ \\
\hline Sm & 0 & $1(5.55)$ \\
\hline PCNA & 0 & $1(5.55)$ \\
\hline Ribosomal-P-protein & 0 & $3(16.67)$ \\
\hline Centromeres B & 0 & $1(5.55)$ \\
\hline PM-Scl & 0 & $1(5.55)$ \\
\hline Histones & 0 & $1(5.55)$ \\
\hline Nucleosomes & 0 & $1(5.55)$ \\
\hline RNP & 0 & $1(5.55)$ \\
\hline \multicolumn{3}{|c|}{ Organ involvement, n [\%] } \\
\hline Articular & $11(68.75)$ & $11(61.11)$ \\
\hline Peripheral nervous system & $5(31.25)$ & $3(16.67)$ \\
\hline Cutaneous & $4(25.00)$ & $3(16.67)$ \\
\hline Pulmonary & $4(25.00)$ & $1(5.55)$ \\
\hline Lymphadenopathy & $3(18.75)$ & $2(11.11)$ \\
\hline Glandular & $1(6.25)$ & $1(6.25)$ \\
\hline \multicolumn{3}{|c|}{ Current treatment, n [\%] } \\
\hline MTX & 0 & $5(27.78)$ \\
\hline NSAID & $4(25.00)$ & $4(22.22)$ \\
\hline Methylprednisolone & $4(25.00)$ & $6(33.33)$ \\
\hline
\end{tabular}

pSS - primary Sjögren's syndrome; sSS - secondary Sjögren's syndrome; BMI - body mass index; MTX - methotrexate; NSAID - nonsteroidal anti-inflammatory drugs; RA - rheumatoid arthritis; SLE, - systemic lupus erythematosus; ESR - erythrocyte sedimentation rate. Unless otherwise stated, data is expressed as median (IQR).

Table 2. Oral and ocular characteristics of SS patients

\begin{tabular}{|c|c|c|}
\hline SS patients $(n=34)$ & $\mathrm{pSS}(\mathrm{n}=16)$ & $\mathrm{sSS}(\mathrm{n}=18)$ \\
\hline PtXer-VAS [mm] & $46.5(52.5)$ & $28.0(47.0)$ \\
\hline Fox's test score [\%] & $45(40)$ & $55(30)$ \\
\hline \multicolumn{3}{|c|}{ Oral symptoms, n [\%] } \\
\hline Dysphagia & $4(25.0)$ & $6(33.33)$ \\
\hline Xerostomia & $9(56.25)$ & $12(66.67)$ \\
\hline \multicolumn{3}{|c|}{ Ocular symptoms } \\
\hline Schirmer's test $[\mathrm{mm}](\mathrm{pSS} n=11, \mathrm{sSS} n=12)$ & $4(8)$ & $10.75(12)$ \\
\hline Dryness of the eyes (subjective assessment), $n$ [\%] & $11(68.75)$ & $13(72.22)$ \\
\hline
\end{tabular}

pSS - primary Sjögren's syndrome; sSS - secondary Sjögren's syndrome; PtXer-VAS - patient xerostomia assessment on visual analogue scale. Unless otherwise stated, data is expressed as median (IQR).
Expression levels of VEGF, EGF, SRSF1, and transcript levels of $V E G F_{165}, V E G F_{165} b$ and $E G F$ in pSS, sSS and HS levels of VEGF and EGF in saliva were significantly higher than in serum. There were no differences between the pSS and sSS group for EGF and VEGF levels. There was also no significant difference in salivary SRSF1 concentration between pSS, sSS and HS. VEGF $165, V E G F_{165} b$ and $E G F$ mRNA expression in pSS patients, sSS patients and HS were at similar levels. Detailed results are presented in Table 3.

There was a statistically significant correlation between VEGF and EGF serum levels in SS patients (Fig. 1). The levels of SRSF1 in parotid saliva correlated positively with the salivary levels of VEGF and EGF (Fig. 2). No statistically significant correlations were found between the gene expression and the other SS activity parameters.

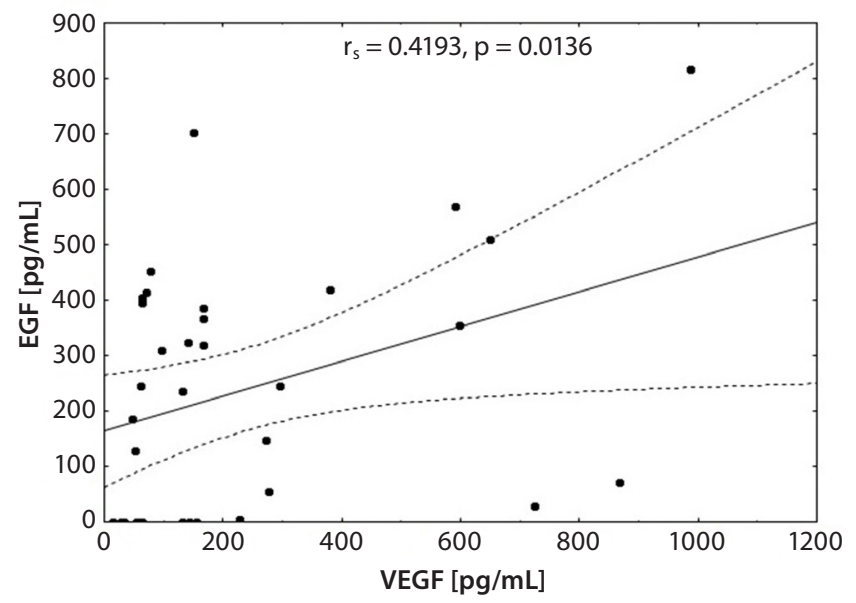

Fig. 1. A positive correlations between serum levels of EGF and VEGF in SS patients. The strength of the relationship was determined by the Spearman's rank correlation coefficient. A p-value of $<0.05$ was considered statistically significant

\section{Discussion}

VEGF contributes to the pathomechanism of SS in many aspects. Recent studies demonstrated a close interplay between VEGF and its receptors in various autoimmune diseases, including SLE, RA, and multiple sclerosis. ${ }^{3,23,24}$ Increased levels of VEGF and VEGFR-1 in plasma were detected in patients with active SLE as compared to the levels in patients with inactive disease and in controls. ${ }^{25}$ Moreover, VEGF was overexpressed in the skin in systemic sclerosis (SSc) and its increased levels correlated with the severity of nailfold capillary loss in SSc. ${ }^{5}$ Considerable amounts of VEGF in both glandular epithelia and inflammatory cells of inflamed glands in SS patients as compared with those from HS were observed. Additionally, an immunohistochemistry examination revealed a strongly positive staining for VEGF and 
VEGFR-2 proteins in the biopsy specimens from SS. Furthermore, anti-Ro/SS-A antibodies enhanced VEGF expression in SS salivary glands biopsy specimens. ${ }^{26,27}$ We obtained contradictory results to the previous studies, because even sSS patients with SLE or RA had no increased levels of VEGF when compared to the controls. Levels of VEGF in parotid saliva were elevated compared to serum levels. This means that the increased levels of VEGF in salivary gland specimens are not reflected in their elevated serum levels. Levels of VEGF and EGF cannot be diagnostic parameters in SS.

Our results confirm that serum and salivary levels of VEGF, EGF as well as PBMC expression of $V E G F_{165}$ and $V E G F_{165} b$ are independent of the type of syndrome and other connective tissue diseases in SSS. In recent studies comparing pSS and sSS, it was found that the intensity and frequency of some symptoms can vary. Similar clinical, serological and histological features with the exception of perivascular infiltrates in the salivary gland biopsies suggests that pSS and sSS are of the same entity. ${ }^{28,29}$ In previous studies, different levels of VEGF and its receptors in SSc and SLE were observed. Ambiguous results can arise from the different classification of $\mathrm{sSS}{ }^{28}$ In our opinion, vasculitis and vasculitic changes are more important issues which should be taken into consideration when VEGF and its isoforms are compared in pSS and sSS. According to Manetti et al., increased plasma levels of $\mathrm{VEGF}_{165} \mathrm{~b}$ isoform are associated with the severity of capillary architectural derangement in SSc patients. ${ }^{6}$ Elevated plasma levels of $V E G F_{165} b$ correlated significantly with the absence of microhemorrhages and the presence of ramified/bushy capillaries and avascular areas. The authors suggested that in SSc patients, the $\mathrm{VEGF}_{165} \mathrm{~b}$ might actively participate in the loss of microvessels. Additionally, the anti-angiogenic $V E G F_{165} b$ splice variant was selectively upregulated at both mRNA and protein levels in the skin biopsy samples from patients with SSc. ${ }^{5}$ No significant difference in skin expression of $\mathrm{VEGF}_{165} \mathrm{~b}$ was found between patients with limited cutaneous SSc and those with diffuse cutaneous SSc. ${ }^{6}$ In our study, the group of patients with vasculitis was too small to include this symptom in statistical analysis and comparison between patients.

In our study, serum levels of VEGF significantly corresponded with the serum levels of EGF. In previous studies, a similar role in the endothelial cell activation by VEGF and fibroblast growth factor 1 and 2 was observed. ${ }^{3}$ Moreover, IGF-1 and TGF- $\beta 1$ have previously been shown to enhance total VEGF expression. ${ }^{9}$ According to Nowak et al.,
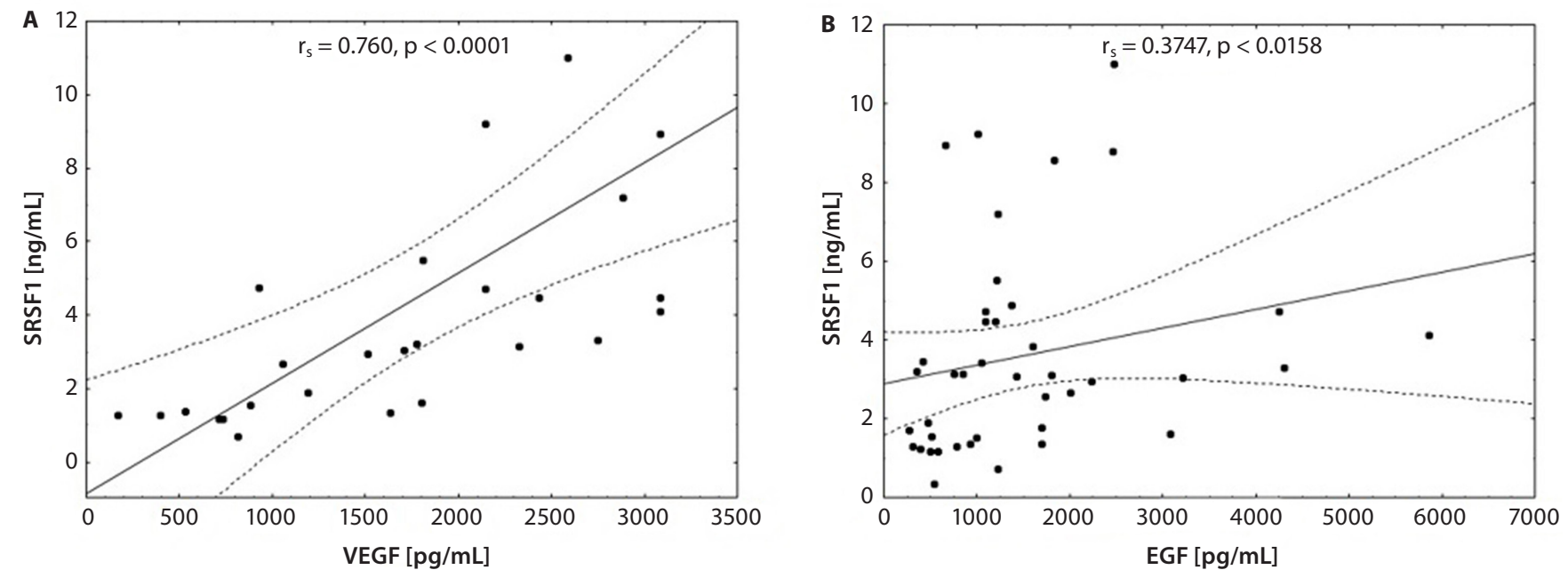

Fig. 2. A positive correlations between salivary levels of VEGF (A), EGF (B) and SRSF1 in SS patients. The strength of the relationship was determined by the Spearman's rank correlation coefficient. A p-value of $<0.05$ was considered statistically significant

Table 3. Levels of VEGF, EGF in serum and saliva in pSS, sSS and HS. Salivary levels of SRSF-1 in pSS, sSS and HS. Expression of VEGF 165, VEGF 165 b and EGF in PBMC in PSS, sSS and HS

\begin{tabular}{|c|c|c|c|c|c|c|c|c|c|c|}
\hline \multirow{2}{*}{$\begin{array}{c}\text { Studied } \\
\text { groups and } \\
\text { comparisons } \\
\text { between pSS, } \\
\text { sSS and HS }\end{array}$} & \multicolumn{3}{|c|}{ VEGF (pg/mL) } & \multicolumn{3}{|c|}{ EGF (pg/mL) } & \multirow[b]{2}{*}{$\begin{array}{c}\text { SRSF-1 } \\
\text { (ng/mL) } \\
\text { saliva }\end{array}$} & \multirow[b]{2}{*}{$\begin{array}{l}V_{E G F_{165}} \\
\text { PBMC }\end{array}$} & \multirow[b]{2}{*}{$\begin{array}{c}V_{E G F_{165 b}} \\
\text { PBMC }\end{array}$} & \multirow[b]{2}{*}{$\begin{array}{c}\text { EGF } \\
\text { PBMC }\end{array}$} \\
\hline & serum & saliva & $p^{a}$ & serum & saliva & $\mathrm{p}^{\mathrm{a}}$ & & & & \\
\hline pSS & $73.83(108.47)^{*}$ & 1348.75 (1264.14) & $<0.001$ & $187.02(390.09)$ & 1003.25 (1571.62) & $<0.001$ & $2.94(2.56)$ & $2.17(0.42)$ & 2.25 (1.19) & $2.29(0.62)$ \\
\hline sSS & $212.58(494.27)$ & $2145.10(1934.22)$ & $<0.001$ & $240.41(376.28)$ & $1215.40(1890.94)$ & 0.003 & $3.90(7.57)$ & $2.18(0.42)$ & $2.27(0.84)$ & $2.35(0.41)$ \\
\hline$p^{b}$ & ns & ns & & ns & ns & & ns & ns & ns & ns \\
\hline
\end{tabular}

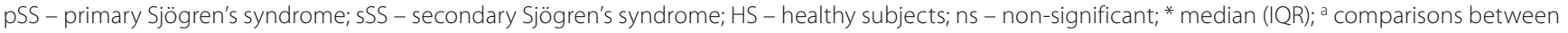
serum and saliva; ${ }^{b}$ comparisons between $\mathrm{pSS}, \mathrm{sSS}$ and HS. 
IGF-1 and TGF- $\beta 1$ and $-\beta 2$ differentially affect the expression of $V E G F_{165}$ and $V E G F_{165} b .{ }^{9} \mathrm{EGF}$ is responsible for the growth of epithelial cells, which are the main targets in the initiation of inflammation and angiogenesis in SS. ${ }^{30}$ Our results confirm that an evaluation of both EGF and VEGF is helpful for gaining a comprehensive view of angiogenesis in SS.

There were no differences in the levels of $V E G F_{165}$ and $V E G F_{165} b$ between pSS, sSS and HS. There were also no statistically significant correlations between the salivary levels of SRSF1 and PBMC expression of $V E G F_{165}$ and $V E G F_{165} b$. But SRSF1 levels correlated positively with total VEGF salivary levels. According to Manetti et al., TGF- $\beta 1$ upregulates the expression of $V E G F_{165} b$ and serine/arginine protein 55 in both SSc and healthy microvascular endothelial cells. ${ }^{6}$ The binding of them to VEGF pre-mRNA or their interaction with VEGF pre-mRNA sequences has been implicated in growth-factor-mediated alternate splice-site selection. Nowak et al. even suggested that known splicing factors differentially affect the expression of the $\mathrm{VEGF}_{\mathrm{xx} x}$ and $\mathrm{VEGF}_{\mathrm{xxx}} \mathrm{b}$ isoform families. ${ }^{9}$ Additionally, VEGFR-1 and neuropilin modulate $\mathrm{VEGF}_{165}$ signaling. ${ }^{31}$ Furthermore, VEGFR-1, fibronectin and collagen also have differentially spliced inhibitory isoforms. A universal mechanism may, therefore, exist for the regulation of these antiangiogenic splicing events. ${ }^{32}$

There were no statistically significant differences in the salivary levels of the selected proteins determined in pSS and sSS patients. According to Hernández-Molina et al., the salivary levels of the pro-inflammatory cytokines were similar in pSS, sSS and pre-clinical SS and systemic autoimmune diseases, but there were differences between $\mathrm{HS}$ and patients with other autoimmune diseases. ${ }^{33}$ Moriyama et al. observed higher levels of pro-inflammatory cytokines in the saliva of SS patients than in those from controls. ${ }^{34}$ According to Bertorello et al., only increased salivary levels of interleukin 10 in SS patients correlate with the severity of the disease. ${ }^{35}$ These differences in the salivary levels of the main cytokines can also stem from vasculitis in SS. ${ }^{36}$ Thus, in saliva it is difficult to find a representative marker with a suitably high specificity to SS.

The limitations of this study can arise from the choice of the type of saliva and the methods of saliva sampling. The levels of salivary peptides vary depending on the type of salivary glands and methods of saliva sampling. Resting and mixed saliva seem to be the most representative oral fluids. On the other hand, mixed saliva consists of crevicular fluid, which can increase the total salivary concentration of proinflammatory cytokines and markers. Stimulation mainly produces parotid saliva, which is easily available for sampling, especially in dry mouth conditions in SS patients. Lack of the measurement of VEGFR2 levels does not provide a comprehensive view of the $\mathrm{VEGF}_{165}$ and $V_{E G F}{ }_{165}$ b relationship. In our study, a few patients were taking methyloprednisolone, non-steroidal anti-inflammatory drugs (NSAIDs) and immunosuppressive drugs. There were no naïve patients regarding both disease-modifying antirheumatic drugs (DMARDs) and NSAIDs. According to Nagashima et al., serum levels of VEGF are reduced by combined therapy with corticosteroids and MTX. ${ }^{37}$ Current and previous therapy and co-existing diseases can interfere with our results, but it is not clear whether these drugs can affect serum and salivary VEGF and EGF levels in SS patients. The main limitations of this study arise from the small sample size. It should, therefore, be considered as a pilot study and our findings have to be verified in a larger SS cohort.

\section{Conclusions}

The balance of VEGF isoforms is not disturbed in SS. Saliva is more sensitive as a medium for detecting EGF and VEGF than serum, but salivary levels of these proteins are not representative for SS group.

\section{References}

1. Fox RI. Sjögren's syndrome. Lancet. 2005;366:321-331.

2. Fox RI, Liu AY. Sjögren's syndrome in dermatology. Clin Dermatol. 2006;24:393-413.

3. Lisi S, Sisto M, D'Amore M, Lofrumento DD. Emerging avenues linking inflammation, angiogenesis and Sjögren syndrome. Cytokine. 2013;61:693-703.

4. Tayama M, Furuhata T, Inafuku Y, et al. Vascular endothelial growth factor 165b expression in stromal cells and colorectal cancer. World J Gastroenterol. 2011;17:4867-4874.

5. Manetti M, Guiducci S, Romano E, et al. Increased plasma levels of the $V_{E G F_{165}}$ b splice variant are associated with the severity of nailfold capillary loss in systemic sclerosis. Ann Rheum Dis. 2013;72:1425-1427.

6. Manetti M, Guiducci S, Romano E, et al. Overexpression of VEGF $F_{165} b$, an inhibitory splice variant of vascular endothelial growth factor, leads to insufficient angiogenesis in patients with systemic sclerosis. Circ Res. 2011;109:14-26.

7. Dokun AO, Annex BH. The VEGF ${ }_{165} \mathrm{~b}$ "ICE-o-form" puts a chill on the VEGF story. Circ Res. 2011;109:246-247.

8. Qiu Y, Ferguson J, Oltean S, et al. Overexpression of VEGF ${ }_{165} \mathrm{~b}$ in podocytes reduces glomerular permeability. J Am Soc Nephrol. 2010;21:1498-1509.

9. Nowak DG, Woolard J, Amin EM, et al. Expression of pro- and antiangiogenic isoforms of VEGF is differentially regulated by splicing and growth factors. J Cell Sci. 2008;121:3487-3495.

10. Rennel ES, Waine E, Guan H, et al. The endogenous anti-angiogenic VEGF isoform, VEGF ${ }_{165} \mathrm{~b}$ inhibits human tumour growth in mice. BrJ Cancer. 2008;98:1250-1257.

11. Rennel ES, Hamdollah-Zadeh MA, Wheatley ER, et al. Recombinant human VEGF $_{165} \mathrm{~b}$ protein is an effective anti-cancer agent in mice. Eur J Cancer. 2008;44:1883-1894.

12. Hua J, Spee $C h$, Kase $S$, et al. Recombinant human VEGF $_{165}$ b inhibits experimental choroidal neovascularization. Invest Ophthalmol Vis Sci. 2010;51:4282-4288.

13. Fox PC, Speight PM. Current concepts of autoimmune exocrinopathy: Immunologic mechanism in the salivary pathology of Sjögren's syndrome. Crit Rev Oral Biol Med. 1996;7:144-158.

14. Vitali C, Bombardieri S, Jonsson R. Classification criteria for Sjögren syndrome: A revised version of the European criteria proposed by the American-European Consensus Group. Ann Rheum Dis. 2002;61:554-558.

15. Westergren A. Diagnostic tests: The erythrocyte sedimentation rate range and limitations of the technique. Triangle. 1957;3:20-25.

16. Najafi L, Malek M, Valojerdi AE, Khamsch ME, Abhaei H. Dry eye disease in type 2 diabetes mellitus; comparison of the tear osmolarity test with other common diagnostic test: A diagnostic accuracy study using STARD standard. J Diab Met Dis. 2015;14. doi:10.1186/ s40200-015-0157-y 
17. Chen A, Chin HT, Hwang $\mathrm{YH}$, Hsiao $\mathrm{CH}$, Chen HC. Severity of dry eye syndrome in related to anti-dsDNA autoantibody in systemic lupus erythrematosus patients without secondary Sjogren sydrome. Medicine. 2016;95:4218.

18. Trzybulska D, Olewicz-Gawlik A, Graniczna K, et al. Quantitative analysis of elastase and cathepsin G mRNA levels in peripheral blood CD14(+) cells from patients with rheumatoid arthritis. Cell Immunol. 2014;292:40-44.

19. Miller-Kasprzak E, Jagodziński PP. 5-Aza-2'-deoxycytidine increases the expression of anti-angiogenic vascular endothelial growth factor $189 \mathrm{~b}$ variant in human lung microvascular endothelial cells. Biomed Pharmacother. 2008;62:158-163.

20. Beştaş R, Kaplan MA, Işikdoğan A. The correlation between serum VEGF levels and known prognostic risk factors in colorectal carcinoma. The correlation between serum VEGF levels and known prognostic risk factors in colorectal carcinoma. Hepatogastroenterology. 2014;61:267-271.

21. Ferreira Duque JL, Loughlin KR, Adam RM, Kantoff P, Mazzucchi E, Freeman MR. Measurement of plasma levels of vascular endothelial growth factor in prostate cancer patients: Relationship with clinical stage, Gleason score, prostate volume, and serum prostate-specific antigen. doi:org/10.1590/S1807-59322006000500006

22. Skopiński P, Skopińska-Różewska E, Jung L, Sommer E, Chorostowska-Wynimko J, Wasiutyński A. Age-dependence of angiogenic activity of human serum. Centr Eur J Immunol. 2009;34:53-56.

23. Carvalho JF, Blank M, Shoenfeld Y. Vascular endothelial growth factor (VEGF) in autoimmune diseases. J Clin Immunol. 2007;27:246-256.

24. Sisto M, Lisi S, Lofrumento DD, D'Amore M, Ribatti D. Neuropilin-1 is upregulated in Sjögren's syndrome and contributes to pathological neovascularization. Histochem Cell Biol. 2012;137:669-677.

25. Robak E, Sysa-Jędrzejewska A, Robak T. Vascular endothelial growth factor and its soluble receptors VEGFR-1 and VEGFR-2 in the serum of patients with systemic lupus erythematosus. Med Inflamm. 2003;12;293-298.

26. Sisto $M$, Lisi S, Ingravallo G, Lofrumento DD, D'Amore M, Ribatti D. Neovascularization is prominent in the chronic inflammatory lesions of Sjögren's syndrome. Int J Exp Path. 2014;95;131-137.
27. Sisto $M$, Lisi S, Lofrumento DD, D'Amore M, Frassanito MA, Ribatti D. Sjögren's syndrome pathological neovascularization is regulated by VEGF-A-stimulated TACE-dependent crosstalk between VEGFR2 and NF-KB. Genes Immun. 2012;13:411-420.

28. Hernández-Molina G, Ávila-Casado C, Cárdenas-Velázquez F, et al. Similarities and differences between primary and secondary Sjögren's syndrome. J Reumathol. 2010;37:800-808.

29. Salliot C, Mouthon L, Ardizzone M, et al. Sjögren's syndrome is associated with and not secondary to systemic sclerosis. Rheumatology. 2007:46:321-326.

30. Mitsias DI, Kapsogeorgou EK, Moutsopoulos HM. Sjögren's syndrome: Why autoimmune epithelitis? Oral Dis. 2006;12:523-532.

31. Wollard J, Wang WY, Bevan HS, et al. VEGF 165 , an inhibitory vascular endothelial growth factor splice variant: Mechanism of action, in vivo effect on angiogenesis and endogenous protein expression. Cancer Res. 2004;64:7822-7835.

32. Díaz R, Peña C, Silva J, et al. p73 isoforms affect VEGF, VEGF ${ }_{165} b$ and PEDF expression in human colorectal tumors: VEGF ${ }_{165}$ b downregulation as a marker of poor prognosis. Int J Cancer. 2008;123:1060-1067.

33. Hernández-Molina G, Michel-Peregrina M, Hernández-Ramírez DF, Sánchez-Guerrero J, Llorente L. Chemokine saliva levels in patients with primary Sjögren's syndrome, associated Sjögren's syndrome, pre-clinical Sjögren's syndrome and systemic autoimmune diseases. Rheumatology. 2011;50:1288-1292.

34. Moriyama M, Hayashida JN, Toyoshima T, et al. Cytokine/chemokine profiles contribute to understanding the pathogenesis and diagnosis of primary Sjögren's syndrome. Clin Exp Immunol. 2012;169:17-26.

35. Bertorello R, Cordone MP, Contini $P$, et al. Increased levels of interleukin-10 in saliva of Sjögren's syndrome patients. Correlation with disease activity. Clin Exp Med. 2004;4:148-151.

36. Roescher N, Tak PP, Illei GG. Cytokines in Sjögren's syndrome. Oral Dis. 2009;15:519-526.

37. Nagashima M, Wauke K, Hirano D, et al. Effects of combinations of anti-rheumatic drugs on the production of vascular endothelial growth factor and basic fibroblast growth factor in cultured synoviocytes and patients with rheumatoid arthritis. Rheumatology. 2000;39:1255-1262. 